\title{
Indicator of Ischemia Syndrome and Reperfusion in Resisted Training
}

\begin{abstract}
Phillipi Leme Dias ${ }^{1}$, Raphael Oliveira Ramos Franco Netto ${ }^{4 *}$,Ligia Maria Gallani ${ }^{1}$, Milene Patricia Costa Camilo ${ }^{1}$, Sandro Percário ${ }^{3}$, Rafael Mâncio ${ }^{2}$, Raphael Oliveira Ramos Franco Netto ${ }^{4}$, Felipe Pedroza Maia ${ }^{5}$, Luan Oennig Col ${ }^{1}$,

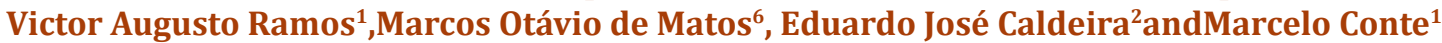

${ }^{1}$ School of Physical Education Jundiaí, Brazil

${ }^{2}$ Faculty of Medicine of Jundiaí, Brazil

${ }^{3}$ Federal University of Pará, Brazil

${ }^{4}$ International UniversityThreeFrontiersUNINTER PJC, Brazil

${ }^{5}$ Brazilian Lutheran University ULBRA, Brazil

${ }^{6}$ Department of Ophthalmology-School of Paulista de Medicina- UNIFESP, Brazil

*Corresponding author: Raphael Oliveira Ramos Franco Netto, Universidad Internacional Tres Fronteiras/Uninter, Ponta Porã, Brazil, Tel: 13202 550/ 11 45871095; Email: raphael_fn@hotmail.com

Submission: 非 February24, 2018; Published: 剕July 03, 2018

\begin{abstract}
Resistance training has been considered as an efficient resource for the control and prevention of pathologies, as well as for the treatment of muscular and joint injuries, rehabilitation of trauma, among others. However, it is known that vigorous physical exercise can increase the formation of free radicals (RL). There are endogenous and exogenous antioxidant mechanisms to combat RL, but when the defense mechanism of the human body is insufficient oxidative stress occurs. The ischemia-reperfusion syndrome, is a mechanism that favors the formation of RL, under these conditions, ammonia is formed and, therefore, it is converted to urea.
\end{abstract}

Objective: To verify the manifestation of oxidative stress in different intensities of resistance exercise through the expression of plasma urea.

Materials andMethods: Eight volunteers were submitted to two sessions of resistance training, the first one (3series with 8RM x 80\% 1RM) and the second one ( 3 series with 8RMx20\% 1RM). Blood samples were obtained before and immediately after the resistance training session to check urea concentrations. The paired Student's t-test was used, adopting a significance level of 5\%.

Result: It was observed that there was a significant increase in urea concentrations after the resistance exercise session at $80 \%$ $(41.25+8.81 \mathrm{vs} .47 .80+12.81 \mathrm{mg} / \mathrm{dl})$. After the $80 \% 1 \mathrm{RM}$ session, plasma urea concentrations were $31.20 \%$ higher than the $20 \% 1 \mathrm{RM}$ session.

Conclusion: Intensive resistance exercise (80\%1RM) should induce ischemia-reperfusion syndrome, and thus increase the formation of RL, interfering with the degree of biomolecular lesion, which may on the other hand induce important antioxidant adaptations.

Keywords:Resistance training; Oxidative stress; Urea; Free radicals

\section{Introduction}

Strength training, also known as resistance training or weight training, has become one of the most popular forms of exercise to improve individual physical fitness and physical fitness of athletes, due to current recommendations to practice physical activities of mild intensity to moderate, can be one of the main factors to guarantee improvement of the quality of life. Resistance training has an uncertain origin, with its historical bases related to Greek mythology. Above all, it has become a cadenced exercise, systematized and subsidized by science and technology [1].

The prescription of resistance training is mainly associated with the determination of load percentages, stratifying the series and repetitions, referencing the exercises, for example, according to the prediction of a maximum repetition (1RM), as suggested by Brzycki. From that point on, resistance work can be associated with specificities such as resistance, hypertrophy, strength and muscular power [2].

On the other hand, there is a correlation between physical exercise and the increase of free radicals. Free radicals are chemical elements whose peculiar characteristics are the exemption from the need to be linked to other molecules to subsist and to have one or more unpaired electrons in the valence layer, generating a great reactive affinity, since they seek to tanger their state equilibrium 
by pairing the odd electron, or losing it to another molecule. This is only possible by means of a chemical reaction [3].

Free radicals also have significant instability, which can serve as a marker for measuring their degree of reactivity, or even a rate that reacts with another substance. By virtue of their reactive spontaneity and high instability, free radicals are able to react with any biomolecule [4], being it protein, lipid, nucleic acid, or even vitamins and carbohydrates, thereby overproducing free radicals will significantly influence the degree of reactions with these biomolecules, altering them in their structural form, and therefore deregulating their systemic activity, thus causing their death, this process is called, Oxidative Stress [5].

However, it is known that vigorous physical exercise provides a certain imbalance between the volume of free radicals expended and antioxidants that minimize the effects promoted by the same, since vigorous exercise maximizes the production of these independent elements [6]. When antioxidant availability is limited, damage by reactive species may result in oxidative stress [7]. However, doubts remain whether in fact the increase of free radicals is a product of muscle tissue lesions suggested by exercise, or as a function of the minimization of total antioxidant capacity (SAD) in favor of tissue repair [8]. One of the implications related to the increase of free radicals through physical exercise is due to the fact that the oxygen supply is significantly higher in the aerobiose, and according to [9]. Powers et al. [7], to promote the increase in twenty times referenced in the basal values, the oxygen is transported in the mitochondrial matrix through the oxidative system [10].

Another way of producing free radicals occurs through anaerobic work, whose phenomenon is known as ischemiareperfusion, characterized by hypoxia, that is, lack of oxygen. During the ischemic process, due to the fact that regional flow is impaired by momentary vascular occlusion during muscle contraction, ie the concentric phase of exercise [11], there is also a deficiency in the availability of oxygen $\left(\mathrm{O}_{2}\right)$ at the moment, therefore, maintenance ergogenic activity occurs mainly through the anaerobic pathway, but in the eccentric phase the muscle receives more blood supply due to the fact that it is relaxing and as a consequence of this fact more oxygen $\left(\mathrm{O}_{2}\right)$ is technically called this phenomenon as ischemia-reperfusion, this process is even more pronounced when exercise is strenuous and ATP regeneration is compromised. Several authors have sought to correlate exhaustive exercise with altered balance between pro and antioxidants in several experimental models $[12,13]$. In this process of ischemia-reperfusion happens the transformation of hypoxanthine into uric acid with release of superoxide [14].

In the resistance exercises, in kind, because they are of high intensity and short duration, the ergogenic substrate responsible for the cellular energy supply is the ATP-Adenosine triphosphate [15], Once depleted by the enzyme ATPase to expend the life energy, ADP (adenosine diphosphate), the availability of creatine phosphate (CP) in muscle tissue is responsible for the regeneration of ATP, combining CP phosphate with ADP, through an enzyme called creatine kinase (CPK), resulting in, in ATP. In fact, the overproduction of ADP through a strenuous energy requirement and in the presence of hypoxia activates an enzyme called myokinase (MK), which synthesizes ATP by binding two ADP (s), and as a byproduct forms adenosine monophosphate (AMP), which in turn stimulates the activation of the AMP deaminase enzyme, which reduces it in inosine monophosphate (IMP) and ammonia $[16,17]$.

The ATP obtained by the anaerobic pathway maintains the ionic pumps, the membrane potential and the contractile function, independent of the acidemia produced by the blood lactate that causes edema to diffuse into the interstitium $[18,19]$.

When the stocks of this energy source are exhausted, the ionic pumps fail and consequently the ionic gradient of the cells change, so there is a potassium and magnesium outlet and sodium and calcium entry into the intracellular environment, causing cellular edema in the matrix and mitochondrial crests [16,20]. More specifically, there is an enzymatic process that starts from the accumulation of intracellular Calcium $\left(\mathrm{Ca}^{++}\right)$, which in turn activates the proteases (calpain), an enzyme responsible for the conversion of xanthine dehydrogenase enzyme to xanthine oxidase, converts the hypoxanthine from the oxidation of IMP to uric acid, and in this process superoxide free radicals $\left(\mathrm{O}_{2}^{-}\right)$are generated [21] hydrogen peroxide and hydroxyl radical [22].

Calcium, in addition to triggering the aforementioned process, can also activate the lysosomal enzyme that directly damages the organelles, as well as the enzyme phospholipase A2 that depredates arachidonic acid giving rise to some precursors of inflammation; are: leukotrienes, prostaglandins, prostacyclin and thromboxane [23]. More specifically, leukotrienes C4 and D4 cause vasoconstriction worsening blood perfusion, thromboxane A2 is also an activator of platelets, neutrophils and still a powerful vasoconstrictor, compromising microcirculation [24]. It is believed that the greatest damage caused by ischemia-reperfusion syndrome occurs in the post-ischemic process, so in reperfusion, specifically, in resistance training the intervals between the series allows the aerobic bioenergetic system to be predominantly, restoring local blood flow within the standard expected to increase the supply of oxygen.

The increase of xanthine oxidase in the skeletal muscle was reported after the resistance training session. It has been observed in studies with rats and humans that there is some inhibition of xanthine oxidase with the supplementation or intraperitoneal application of allopurinol (xanthine oxidase inhibitor), which minimizes the oxidation of glutathione, and was also able to decrease muscle injury markers after intense physical exercise, thus reinforcing the role of xanthine oxidase as the main source of ROS production in high-intensity exercise [25].

It is important to emphasize that the release of urate is concomitant with the release of the free radical, which can be expressed in organisms in various ways and by various means, so that the free radical can be glimpsed through direct pathway signaling: total antioxidant rate (ESR); plasma analysis of 
malondealdehyde (MDA) [26], carboline protein among others; or by the indirect method, for example, by analyzing the expression of urate and urea that are products of the biochemical reactions of the ischemia-reperfusion syndrome.

One of the indirect ways to analyze the release of free radicals is through uric acid. The catabolism of nucleic acids forms the purines, since degraded they are precursors of the uric acid, in a reaction whose xanthine oxidase participates, this in turn can for example be inhibited by the drug allopurinol, that has been studied in the process of minimization of ischemia-reperfusion in the kidneys, as well as renal insults [27]. The decrease in the action of xanthine oxidase causes less uric acid formation and increased urinary excretion of hypoxanthine and xanthine, both precursors of uric acid [28] and when there are ingestion of certain types of foods containing purines the expression of uric acid can increase, therefore hypoxanthine, xanthine, allantoin and uric acid are products of catabolism of purines, which may be those that have been absorbed in the intestine and endogenously, that is, generated in the metabolism of nucleic acids [29].

Another way these substances increase in the body is through an amino acid-related diet; the excretory form of hypoxanthine, xanthine, allantoin and uric acid begins after intestinal digestion of the purine nucleotides through the duodenal flow, which have essentially microbial resources for this, subsequently there is the catabolism of the nitrogenous bases (adenine and guanine) and urinary excretion of the same in conjunction with the abovementioned substances.

The level of uric acid expressed depends on genetically determined metabolic factors, as well as enzymatic activity, nutritional factors and also on the efficiency of renal excretion.On the other hand, urea is also an important marker of system intensity (ischemia-reperfusion)[30,31]. It is a colorless, crystalline organic compound with the formula $\left(\mathrm{NH}_{2}\right) 2 \mathrm{CO}$, which can be synthesized in the liver through ammonia, filtered by the kidneys and excreted in urine or sweat. The urea cycle in the liver occurs from the ammonia, which is constituted by nitrogen and hydrogen, being in nature in gaseous form $\left(\mathrm{NH}_{3}\right)$ and eminent solution in the form of ammonium $\left(\mathrm{NH}_{4}+\right)$. In aqueous solution the $\left(\mathrm{NH}_{4}+\right)$ is formed from $\left(\mathrm{NH}_{3}\right)$ in the equilibrium reaction $\mathrm{NH}_{3}+\mathrm{H}+[31]$. The synthesis of ammonia also occurs by means of decomposing bacteria in the terrestrial soil and by the degradation of amino acids and nucleotides made by animals, which excrete in the form of ammonia, urate (urotélicos), or in the form of urea) [32]. For detoxification since ammonia has a significant level of toxicity to the body, it needs to be dislodged to the blood for the purpose of detoxification [33], it is referred to the urea cycle, whose mitochondria hepatocytes convert to urea $[34,35]$.

Urea is produced from ammonia in five enzymatic phases, two of them inside the mitochondria of hepatocytes and three in the cytosol, mainly involving the conversion of ornithine to arginine, both amino acids. L-Arginine is an extremely versatile amino acid being involved in a significant range of metabolic pathways, as well as in the urea cycle; two amino groups participate in the cycle, being the first derivative of the ammonia located inside the mitochondria [36], also originating from the deamination, or even brought from the intestine, whose production occurs through the bacteria that oxidize the groups of amino acids (via port), this is mediated by the synthesis of carbamoyl phosphate together with bicarbonate $\left(\mathrm{HCO}_{3}-\right.$ ) which is the product of mitochondrial respiration, the second amino group is supplied by aspartate generated by mitochondrial transamination, and is therefore transported to the cytosol [37]

The Asp once formed in the mitochondria by transamination between oxaloacetate and glutamate (Glu) can be transported to the cytosol, whose function is to donate nitrogen in the reaction of the urea cycle catalyzed by argininosuccinatosintetase [38]. The formation of urea is directly related to a cascade of reactions whose final process culminates in the release of hydroxyl.

Therefore, by analyzing the plasma urea content, it is also possible to infer how expressive free radical formation was through an indirect pathway during the ischemia-reperfusion syndrome process, it is important to understand how these highly reactive chemical species behave from different types of stimuli in terms of physical exercise, glimpsing the meaning that has the intensity and the volume of work performed. Thus, the objective of this work was to verify the manifestation of oxidative stress in different intensities of resistance exercise through the expression of plasma urea

\section{Materials and Methods}

Experimental study with eight individuals selected for accessibility [39], according to the following inclusion criteria:

\section{A. Male}

B. Age between 18 and 30years

C. Intermediate level of resistance training (with continuity of resistance training minimum of six months and maximum of 36 months).

The subjects did not have any type of pathology that impeded the perfect execution of the suggested activities within the research, nor did they present any type of joint limitation, nor did they ingest anabolic substances, dietary supplements and any other drugs that influenced the development of the research.The protocol was conducted following the ethical principles set forth in the Declaration of Helsinki proposed by the World Association of Physicians [40]. The project was submitted to the Research Ethics Committee of the Superior School of Physical Education of Jundiaí. All participants were informed about the research and the degree of involvement. It was requested the signing of the Term of Free and Informed Consent [41].

The volunteers were submitted to two sessions of resistance exercise, being collected, before and immediately after the sessions [42], blood samples were collected by a professional in the nursing area. The training sessions were elaborated according to two training models of high and low intensity, the first with 3 sets of 8 repetitions with $80 \%$ of the RM and the second session 3 sets of 8 repetitions with $20 \%$ of the RM (Table1). The exercises were

How to cite this article: Phillipi L D, Raphael O R F N,Ligia M G, Milene P C C, Sandro P, Rafael M, Raphael O R F N, Felipe P M, Luan O C, Victor 
selected due to the fact that they were considered basic, precisely because they involved large muscle groups, multi-articulates, as well as prioritizing the main muscle groups.

Table 1: Description of strength training sessions.

\begin{tabular}{|c|c|c|c|c|}
\hline Exercise & Series & Repetitions & Intervals & \% RM \\
\hline Supine & 3 & 8 & $90^{\prime \prime}$ & 80 and 20 \\
\hline Squat & 3 & 8 & $90^{\prime \prime}$ & 80 and 20 \\
\hline Dorsal Knob & 3 & 8 & $90^{\prime \prime}$ & 80 and 20 \\
\hline Deadlift & 3 & 8 & $90 "$ & 80 and 20 \\
\hline Deltoid Development & 3 & 8 & $90 "$ & 80 and 20 \\
\hline Direct Thread & 3 & 8 & $90 "$ & 80 and 20 \\
\hline
\end{tabular}

Initially, to determine the loads of the exercise sessions, the 1RM prediction test was performed, which consisted of performing submaximal loading until exhaustion. This test was applied in all exercises described in the proposed resistance training program [43]. The volunteers were instructed not to perform physical exercise in the 48 hours prior to the respective test. The collected blood sample was centrifuged in a dry tube at 3000rpm for 10 minutes, and the result immediately delivered by Advia ${ }^{\circledR}$ [44]. The paired Student's t-test was used as statistical procedure to compare means for the variables studied, adopting a significance level of 5\%. The software used was GraphPadPrism ${ }^{\circledR}$.

\section{Result}

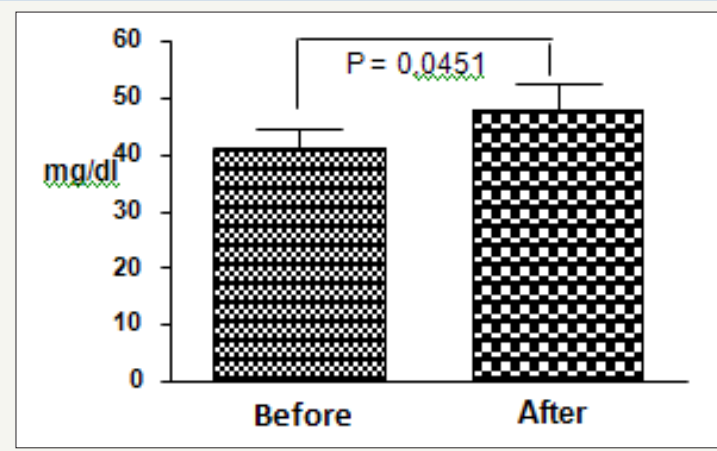

Figure 1: Comparison of urea concentrations before and after the exercise session $80 \% 1$ RM.

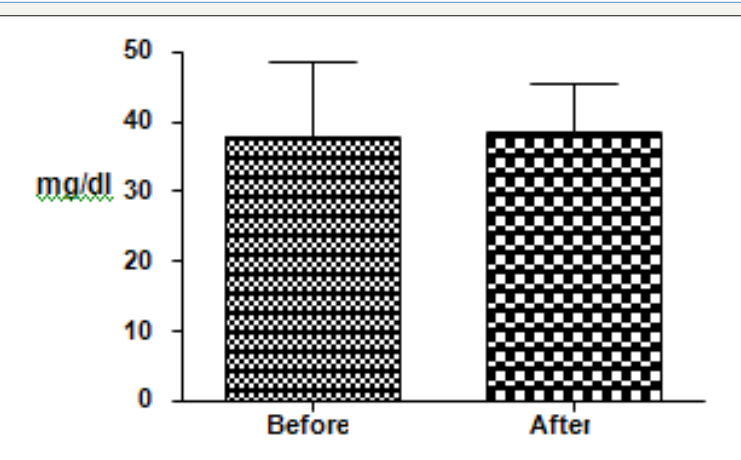

Figure 2: Comparison of urea concentrations before and after the exercise session $20 \% 1$ RM.
It was observed that there was a significant increase in urea concentrations after the resistance exercise session at $80 \%$ $(41.25+8.81 \mathrm{vs} .47 .80+12.81 \mathrm{mg} / \mathrm{dl})$ [45], that is, an increase of approximately $16 \%$ of urea (Figure 1 ). In the $20 \%$ exercise session (Figure 2), the urea increase was irrelevant (37.96+12.54 vs. 38.44 $+15.72 \mathrm{mg} / \mathrm{dl}$ )

When comparing urea concentrations after the two exercise intensities, it was observed that concentration after exercise resisted at $80 \% 1 \mathrm{RM}(55.97+7.32 \mathrm{mg} / \mathrm{dl})$ was higher than in the $20 \% 1 \mathrm{RM}$ session $(38,44+15.72 \mathrm{mg} / \mathrm{dl})$ [46], but this difference was not statistically significant. Descriptively, the $80 \% 1 \mathrm{RM}$ session presented urea plasma concentrations $31.20 \%$ higher than the 20\% 1RM session (Figure 3).

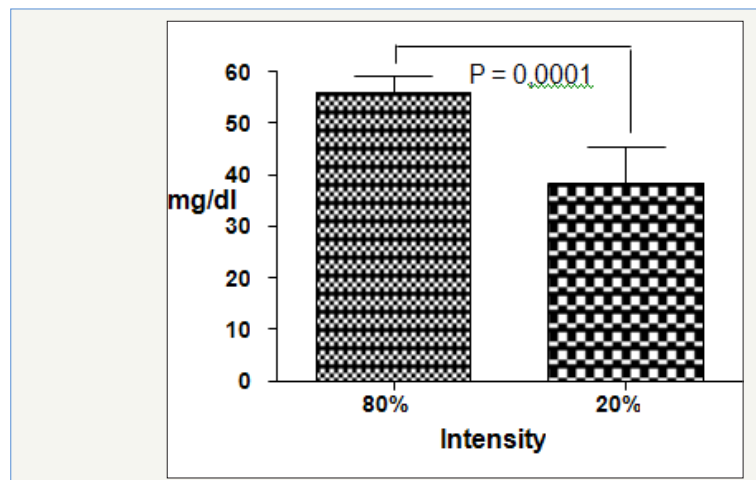

Figure 3: Comparison of urea concentrations after exercise at $80 \%$ and $20 \% 1 \mathrm{RM}$.

It is important to note that, for individuals in this age group, the reference values of urea are 10 to $40 \mathrm{mg} / \mathrm{dl}$, it can be observed that the volunteers evaluated presented in the conditions of $80 \%$ of $1 \mathrm{RM}$ scores higher than the values recommended as normal

\section{Discussion}

The results showed increased expression of urea by the stimulation of the resistance exercise. In the final process of the ischemia-reperfusion syndrome [47], where there is release of adenosine monophosphate (AMP), which in turn stimulates the activation of the AMP deaminase enzyme, responsible for reducing AMP in inosinamonophosphate (IMP) and ammonia (Figure 1), being it transformed into a substance less deleterious for preservation of the integrity of the organism.

As previously mentioned, ammonia is toxic and the concentrations in the systemic circulation are regulated by a coordinated process, in which the glutamine (GLN) [48], which can transport the ammonia in the current In order to achieve this, ammonia is combined with glutamate (GLU) through an enzyme called glutamine synthetase (GS) to release and form GLN; once released and representing a non-toxic form of ammonia, can be transferred to the blood, subsequently displaced to the kidneys and liver where by means of an enzyme called glutaminase it is transformed into GLU and ammonia so that the urea cycle can happen. Once the ammonia has undergone transformation and has become a less toxic substance (urea), it returns to the systemic circulation through an exchange of organs [49], more specifically 
between the gastrointestinal tract, liver and kidneys that provide important homeostasis of the concentration of ammonia, however, other organs and tissues such as the brain and skeletal muscle play an important role in the metabolism and regulation of this system [50], and can be eliminated in urine or used to maintain [51].

This efficient detoxification mechanism allows plasma ammonia concentrations to be maintained within a small range and no more than $50-100 \mu \mathrm{mol} / \mathrm{L}$. Therefore, the highest concentration of urea in the body when compared to expected values for individuals in the studied age group (10 to $40 \mathrm{mg} / \mathrm{dl}$ ), indicates that the ischemiareperfusion process was intensified, mainly through the resistance exercise program with intensity of $80 \% 1 \mathrm{RM}$. Resistance training protocols that use intensities from 50\% 1RM are sufficient to promote significant ischemia [52], and thus capable of triggering the ischemia-reperfusion syndrome process, evident in the present study. There is a possibility of increasing the concentration of urea in the body through the ingestion of some types of food that are initially reduced to ammonia, more specifically the ammonia generating sources are derived from the putrefactive activity of the bacteria on the nitrogenous compounds that it comes from the intestinal contents, as well as processes of oxidative deamination, transamination of the amino acids of the diet and the tissues; and by the nucleotide purine cycle, via AMP deamination [53].

Accordingly, by increasing the volume of ammonia, the synthesis of urea for detoxification is also increased; In this sense, the intake of foods and products containing amino acids may influence urea plasma concentrations, however, the individuals studied were oriented not to consume any type of food supplement or ergogenic resource; especially those containing proteins and amino acids to avoid influencing the results, so the effects of plasma urea were not interfered with by synthetic supplies, only direct interference of the exercises proposed for the study [54], since volunteers did not supplement before, during or after the train.

More specifically when amino acids are displaced into the hepatic cytosol; initially they undergo a catabolic action, that is [55], degradation; more specifically there is removal of the amino group, and this process takes place through the enzyme aminotransferase, from this transamination reaction the amino group that has been secreted is transferred to the carbon of the 2-oxoglutarate which is a ketoacid, respectively producing the alpha-keto acid (keto analogue) of the amino acid and Glu. The purpose of transamination is to extract and concatenate various amino groups of many different amino acids in the form of only one, Glu; these reactions can be reversed and used for amino acid synthesis from the keto analogue [56].

Since Glu is transported to the liver cell cytosol (hepatocytes) inside the mitochondria, it undergoes oxidative deamination through glutamate dehydrogenase (GDH) [57], located only in the mitochondrial matrix; and the result of this action is the formation of 2-oxoglutarate and ammonia. The ammonia produced is referred to the urea cycle in the mitochondria of hepatocytes with the purpose of having converted, therefore in urea. In this perspective, the signaling of these indirect markers of oxidative stress is also related to eating habits, as well as adaptation to exercise, since trained individuals have a more efficient energy resynthesis (ATP) capacity when compared to untrained individuals.In terms of practical applications [58], this study showed that resistance training with intensity at $80 \% 1 \mathrm{RM}$ promotes urea increase, which suggests the manifestation of ischemia-reperfusion syndrome. This phenomenon supposes that on the one hand the increase of the free radicals in the organism can bring some important physiological adaptations.

Free species derived from oxygen are produced naturally in the body through oxidative metabolic processes, and are often very useful for stimulating the immune system, such as macrophages that destroy some bacteria and others by means of hydrogen peroxide strange elements; or in the process of detoxification of drugs whose free radicals also play an important role [59], as well as in the production of endothelium-derived relaxing factor, nitric oxide, crucial for the process that triggers the relaxation of blood vessels [60]. Weight-bearing exercise delivered at $80 \% 1 \mathrm{RM}$ as the study performed is characterized within the nature of weight training, such as muscle hypertrophy. More specifically, the strength of the exercise resisted according to the literature for strength gains and muscular hypertrophy is always higher than 60\% 1RM, and in most studies the suggested intensity is $80 \% 1 \mathrm{RM}$, and the number of repetitions varies between six and twelve repetitions [61].

The work of hypertrophy results in microlesions and rupture of sarcomeres, decreases the ergogenic stock, through specific physiological adaptations and these responses occur through constant overload and periodic training [62]. Thus, muscle hypertrophy consists of increased cross-section of skeletal muscle translated by increasing the number of actin and myosin filaments. Strength training promotes increased muscle section, and fasttwitch fibers seem to respond better to hypertrophy [63]. All this process is mediated by extracellular signals that interact with receptors on the cell surface, activating signaling pathways that modify gene expression, remodeling the muscle fiber [64].

The hypertrophic process is modulated by the increase of nuclei in the intracellular portion, making gene transcription feasible, as well as the increase of the cytoplasmic volume. In this adaptive perspective, the literature suggests certain stimuli as responsible for the hypertrophic response induced by physical exercise. Among them, the following are the mechanics promoted by muscle contraction [65], the alteration in the cellular energy state due to a specific time of stimulation of the metabolic pathways of ATP resynthesis [66], the endocrinological interactions, growth factors and certain nutrients that stimulate the onset of the cascade of intracellular gene transcription reactions [67], as well as the activation of the satellite cells (CS), which are responsible for the insertion of new myonuclei [68].

Endocrine adjustments modulate important adaptations to provide overcompensation after strength training. The system that modulates these acute changes in the physiological balance responds through stimuli based on physical exercise, more specifically for the regulation of protein metabolism and small 
changes to more or less in the immune system [69]. There are studies that demonstrate the expressive increase of testosterone when the exercises are high intensity and bulky, especially when large muscle groups are recruited [70].

One of the most anabolic hormones in the work force approach is testosterone, which acts directly on the expression of muscle protein content, and indirectly influences the growth hormone (GH) synthesis, promoting the release of IGF-1. According to, human GH has important expression during strength training and after 30 minutes. GH is responsible for secretion of insulin-like factors (IGF1) in hepatic cells [71], and in this sense many studies have shown that strength training provides an increase in the amount of insulin (1) and (2), respectively. In addition, there is a higher release of this hormone in the musculature acting in a paracrine and autocrine form.

According to the literature, all the biochemical and physiological adaptations mentioned above are crucial for the development of muscular hypertrophy, and the margin of the training system whose intensity is equal to or approximately $80 \% 1 \mathrm{RM}$ seems to be the best to allow the whole process [72], in fact, the expenditure of highly reactive chemical species responded within a more significant expression precisely in this working range, which could indicate muscle hypertrophy with an indirect marker of the behavior of these free radicals stimulated by a specific hypertrophic work system.

On the other hand, it is widely recognized that the exercise of force promotes in an acute way the increase of the hormonal expression. From this perspective it is known that the hormonal profile is related to the energy metabolism and ROS production. Studies have shown that hormones influence antioxidant defenses, and thus hyposecretion or hormonal hypersecretion may influence [73]. Therefore, according to Brown Borg [74], the enzymatic changes in the hormone-mediated antioxidant system appear to be tissue-specific and dose-dependent.

In this perspective [75] in an experiment with miceadministering GH demonstrated the increase of the enzyme catalase, which is an antioxidant, thus leading to an improvement in the defense system against free radicals. Although the muscular hypertrophy system within the strength training may indirectly infer greater oxidative stress, training with intense loads also promotes greater expenditures of some hormones during and after training, which are important mediators of the immune system, whose adaptation to the Oxidative stress stimulated by high intensity exercise is essential for maintaining good health. For Reighlin et al. [76], the relationship between the immune system and the neuroendocrine system is very clear

Biomolecular adaptations to protect against oxidative stress are very important to the body, and (ROS) are continuously formed in small amounts by a natural and inevitable metabolic process. It is important to note that the defense system for these highly reactive chemical species varies from tissue to tissue, cell type, and from cell to cell in tissues [77].
According to Health 1981, after accompanying athletes for many years observed that the metabolic potential of these individuals was not harmed by free radicals, which in the 1980s were already known for their potential for aging, in this sense Gutteridge and colabodardores [78] suggested as a possible protective mechanism against physical exercise (ROS), precisely because they found a certain expression of iron and copper in the sweat of athletes after exercise, thus suggesting that the excretion of these metals in sweating would be able to decrease the expression of free radicals also occurring through the transition metals. From this premise the possibility arose that regular physical exercise could be a protectionist resource against the lesions produced by oxidative stress.

It was reported in the 1990s [41,79] that working with an isolated load on skeletal muscle was able to increase lipid peroxidation (LPO), as well as the expression of the glutathione reductase, GPx, SOD and CAT enzymes that are antioxidants. More specifically according to Alessio [80], the cellular damage caused by lipoperoxidation in slow and fast muscle fibers in rats submitted to weight exercises was increased, thus indicating greater oxidative stress mediated by physical activity. On the other hand, stress was better tolerated by trained rats, suggesting that physical exercise promotes improvement in the adaptive defense system against free radicals. In this sense, the increase in the expression of free radicals mediated by exercise can be beneficial, since it stimulates a specific adaptation system to improve the degree of defense against cellular lesions and thus promoting favorable conditions for the antioxidants to act.

The antioxidant system can be divided into enzymatic and nonenzymatic; (SOD), catalase (CAT) and glutathione peroxidase (GPx). Catalase, for example, is responsible for reacting as the free radical hydrogen peroxide $\left(\mathrm{H}_{2} \mathrm{O}_{2}\right)$ in a reaction in which the end product is water $\left(2 \mathrm{H}_{2} \mathrm{O}\right)$ and oxygen $\left(\mathrm{O}_{2}\right)$; in the same way that glutathione dexixase (GPx) is very important in the minimization of the radical $\left(\mathrm{H}_{2} \mathrm{O}_{2}\right)$, since it converts reduced glutathione (GSH) to glutathione oxidase (GSSG), which removes $\mathrm{H}_{2} \mathrm{O}_{2}$ and produces $\left(2 \mathrm{H}_{2} \mathrm{O}\right)$ [58]. Thus, the antioxidants (CAT) and (GPx) decrease the accumulation of the radical superoxide and hydrogen peroxide, preventing the formation of hydroxyl, for which there is a specific enzymatic defense system [81]

On the other hand the non-enzymatic defense system compose some substances endogenously synthesized in the human organism such as bilirubin, ceruloplasmin, sex hormones, melatonin, coenzyme Q, uric acid; and others that can be obtained exogenously through diet; as mentioned above vitamins $\mathrm{A}, \mathrm{C}$ and $\mathrm{E}$; which assist enzymes indirectly for the process of minimizing oxidative stress [82]. The adaptations in the antioxidant system are related to the intensity of the work performed [83] so the type of work proposed at intensity level seems to matter so that there is adequate adaptation; as previously mentioned; if antioxidant resources are insufficient to counteract the level of free radicals released, there will be oxidative stress, damaging the cell and causing its death $[84,85]$. 


\section{Conclusion}

Intensive resistance exercise ( $80 \% 1 \mathrm{RM})$ may induce ischemiareperfusion syndrome, thus increasing RL formation, interfering with the degree of biomolecular injury, which may on the other hand induce important antioxidant adaptations.

\section{References}

1. Fleck S, Kraemer (2006) Fundamentos do treinamento de força muscular $\left(4^{\text {th }} \mathrm{edn}\right)$, Porto Alegre, Brazil.

2. Bompa To, Corachia LJ (2000) Treinamento de força consciente.

3. Halliwell B, Gutteridge JMC (1999) Free radicals in biology and medicine. Oxford, Clarendon Press, UK.

4. Schröder H, Navarro E, Mora J, Galiano D, Tramullas A (2001) Effects of alpha-topherol, beta carotene and ascorbic acid on oxidative, hormonal and enzymatic exercise stress markers in habitual training activity of professonal basketball players. Eur J Nutr 40(4): 178-184

5. Swanson C (1998) Vegetables, fruits, and cancer risk: The role of photochemical. In: bidlack WR, Omaye ST, Meskin MS, Jahmer D (Eds.), Phytochemicals: a new paradigm. Technomic Publishing, Lancaster PA, USA, pp. 1-12.

6. Adams Ak, Best TM (2002) The role antioxidants in exercise and disease prevention. Phys Sports med 30(5): 37-44.

7. Powers SK, Howley ET (2006) Fisiologia do exercício: teoria e aplicação ao condicionamento e ao desempenho. ( $8^{\text {th }}$ edn), São Paulo, Brazil.

8. Tortora, Grabowski (2000) Princípios da anatomia e fisiologia. Rio de Janeiro, Brazil.

9. Lew H, Pyke S, Quintanilha A (1985) Changes in the glutathione status of plasma, liver and muscle following exhaustive exercise in rats. FEBS Lett 185(2): 262-266.

10. Mcanulty SR, McAnulty LS, Nieman DC, Morrow JD, Shooter LA, et al. (2005) Effect of alpha-tocopherol supplementation on plasma homocysteine and oxidative stress in highly trained athletes before and after exhaustive exercise. J Nutr Biochem 16(9): 530-537.

11. Seguro AC (1994) Lesão celular na isquemia renal. In: CRUZ J (Ed.), Atualidadesem Nefrologia, São Paulo, Sarvier, Brazil.

12. Sjodin B, Hellsten WY, Apple FS (1990) Biomechanisms for oxygen free radical formation during exercise. Sports Med 10(4): 236-254

13. Percário, Domingues SP, Teixeira LF, Vieira JL, De Vasconcelos F, et al. (2012) Effects of creatine supplementation on oxidative stress profile of athletes. J Int Soc Sports Nutr 9(1): 56

14. Moreno Jb (1991) Efeito de alfa tocoferol na atenuação da lesão deisquemia-reperfusão em membro posterior do rato [dissertação] Faculdade De Medicina de Botucatu, Botucatu, Brazil.

15. Francischetti I (2001) Estudos da ação do Estudo da ação do ácido trissódio-cálciodietileno-triaminopenta acético (CaNa3DTPA) nas lesões deisquemia e reperfusão em membro posterior de rato [dissertação] Faculdade de Medicina de Botucatu, Botucatu, Brazil.

16. Morin D, Hauet, Spedding M, Tillement J (2001) Mitochondria as target for ant ischemic drugs. Adv Drug Deliv Rev 4(2): 151-174.

17. Percario S (2000) Alterações oxidativas e da defesa antioxidante no Broncoespasmo agudo induzido em cobaias. Tese (Doutorado) apresentada à Universidade Federal de São Paulo, Brazil.

18. Rhoden EL, Mauri M, Petteffinns L, Dacanal F, Pilla M, et al. (1998) Efeitos do alopurinol sobre a lipoperoxidação de membranas celulares renais na síndrome da isquemia e reperfusão: Estudo experimental em ratos. Acta Cir Bras 13(2): 73-79.

19. Burgunder JM, Varriale A, Lauterurg BH (1989) Effect of N-acetylcysteine on plasma cysteine and glutathione following paracetamol administration. Eur J Pharmacol 36(2): 127-131.

20. Gomes MD, Lecker SH, Jagoe RT, Navon A, Goldgerg AL (2001) Atrogin-1, a muscle-specific F-box protein highly expressed during muscle atrophy. Proc Natl Acad Sci U S A 98 (25): 14440-14445.

21. Bosoi CR, Rose CF (2009) Indentifying the direct effects of ammonia of the brain. Metab Brain Dis 24(1): 95-102.

22. Nelson, Dl Cox MM (2005) Lehninger: principles of biochemistry, $\left(4^{\text {th }}\right.$ edn.), Freeman, USA.

23. Graham TE, Maclean DA (1992) Ammonia and amino acid metabolism in human skeletal muscle during exercise. Can Physiol Pharmacol 70(1): 132-141.

24. Shambaug GE $3^{\text {rd }}$ (1977) Ureia biosynthesis I. The urea cycle and relationships to the citric acid cycle. Am J Clin Nutr 30(12): 2083-2087.

25. Wu G (2009) Amino acids: metabolism, functions and nutrition. Amino acids 37(1): 1-17.

26. Ministério DA (1996) Informe Epidemiológico do SUS. Suplemento 3: 2.

27. Olde SW, Deutz NE, Dejong CH, Soeters PB, Jalan R (2002) Interoganammoniametabolism in liver failure. Neurochem Int 41(2-3): 177-188.

28. Adams GR, Cheng DC, Haddad F, Baldwin KM (1985) Skeletal muscle hypertrophy in response to isometric, lengthening and shortening training bouts of equivalent duration. J Appl Physiol 96(5): 1613-1618.

29. Souza JT, Oliveira PR, Pereira B (2005) Exercício físico e estresse oxidativo: efeitos do exercício físico intenso sobre aquimioluminescência urinária e malondialdeídoplamático. Rev Bras Med Esporte 11(1): 9196.

30. Wagenmakers AJ, Brookes JH, Coakley JH, Reilly T, Edwards RH (1989) Exercise induce activation of the branched-chain 2-oxo acid dehydrogenase in human muscle. Eur J App Physiol Occup Physiol 59(3): 159-167.

31. Moncada S, Higgs A (2001) Nitric oxide: role in human disease. Encyclopedia of Life Sciences.

32. American College of Sports Medicine (2002) American college of sports medicine position stand: progression models in resistance training for healthy adults. Med Sci Sports Exerc 41(3): 687-708.

33. Uchida MC (2003) Manual De musculação. São Paulo: Phorte, Brazil.

34. Bassel DR, Olson EN (2006) Signaling pathways in skeletal muscle remodeling. Annu Rev Biochem 75: 19-37.

35. Tidaball JG (2005) Mechanical signal transduction in skeletal muscle growth and adaptation. J Appl Physiol 98(5): 1900-1908.

36. Fluck M, Dapp C, Schmutz S, Wit E, Hoppeler H (2005) Transcriptional profiling of tissue plasticity: role of shifts in gene expression and technical limitations. J Appl Physiol 99(2): 397-413.

37. Kraemer WJ, Ratamess NA (2005) Hormonal responses and adaptations to resistance exercise and training. Sports Med 35(4): 339-361.

38. Hill M, Werning A, Goldspink G (2003) Muscle satellite (stem) cell activation during local tissue injury and repair. J Anat 203(1): 89-99.

39. Fleck S, Kraemer (2006)Fundamentos do treinamento de força muscular, Porto Alegre, Brazil.

40. Volek JS, Kraemer WJ, Bush JA, Incledon T, Boetes M (1997) Testosterone and cortisol in relationship to dietary nutrients and resistance exercise. Journal of applied Physiology 82(1): 49-54

41. Brown-Borg HM, Bode AM, Bartke A (1999) Antioxidative mechanisms and plasma growth hormone levels: Potencial relationship in the aging process. Endocrine 11: 41-48.

How to cite this article: Phillipi L D, Raphael O R F N, Ligia M G, Milene P C C, Sandro P, Rafael M, Raphael O R F N, Felipe P M, Luan O C, Victor A R,Marcos O d M, Eduardo J C,Marcelo C. Indicator of Ischemia Syndrome and Reperfusion in Resisted Training. Gerontol \& Geriatric Stud .3(4). GGS.000569.2018. DOI: 10.31031/GGS.2018.03.000569 
42. Ji LL, Fu R (1992) Responses of glutathione system and antioxidant enzymes to exhaustive exercise and hydroperoxide. J Appl Physiol 72: 549-554.

43. Yu BP (1994) Cellular defenses against damage from reactive oxygen species. Physiol Rev 74: 139-162.

44. Goode HF, Webster NR (1993) Free radicals and antioxidants in sepsis. Crit Care Med 21(11): 1770-1776.

45. Margaritis I, Tessier F, Richad MJ, Marconnet P (1997) No evidence of stress after a triathlon race in highly trained competitors. Int J Sports Med 18(3): 186-190.

46. Aguiló A, Tauler P, Fuentespina E, Tur JA, Córdova (2005) A antioxidan response to oxidative stress induced by exhaustive exercise. Physiology \& Behavior 84(1): 1-7.

47. Alves AA (2002) Marcadores do estresse oxidativo induzido pelo exercício físico e tecnologia para sua quantificação. Instituto de Biologia. Universidade Estadual de Campinas, Brazil.

48. Banister WE, Cameron BJ (1990) Exercise induced hyper ammonemia: peripheral and central effects. Int J Sports Med 11(Suppl 2): S129-S142.

49. Brown Borg HM, Rakoczy SG (2003) Growth hormone administration to long-livingdwarf mice alters multiple components of the antioxidative defense system. Mech Ageing Dev 124(10-12): 1013-1024.

50. Brzycki M (1993) Strength testing: predicting a one-rep max from reps to fatigue. Journal of Physical Education, Recreation and Dance 64: 8890 .

51. Clarkson PM, Thompson HS (2000) Antioxidants: what role do they play in physical activity and health? Am. J Clin Nutr 72: 637-646.

52. Chetham ME, Boobis LH, Brooks S, Williams C (1986) Human muscle metabolism during sprint running. J Appl Physiol 61(1): 54-60.

53. Contreras GO, Meléndez MG, Zúñiga RA, Pasquetti CA (2004) Antioxidantes y aterosclerosis. Revista de Endocrinología y Nutrición 12 (4): 199-206.

54. Cooper CE, Vollaard NB, Choueiri T, Wilson MT (2002) Exercise, free radicals and oxidative stress. Biochemical Society Transactions 30(2): 280-285.

55. Crystal RG (1991) Oxidants and respiratory tract epithelial injury: pathogenesis and strategies for therapeutic intervention. Am J Med 91 $39-44$.

56. Ernani LR, Márcio LL, Cláudia RR, Cláudio GZ, Angelo AM (2015) Efects of $\mathrm{L}$-arginine and L-name on renal ischemia-reperfusion in rats. Brazilian Journal of Urology 30(5): 78-83.

57. Evans WJ (1999) Exercise training guidelines for the elderly. Med Sci Sports Exerc 31(1): 12-17.

58. Feigenbaum MS, Pollock ML (1999) Prescription of resistance training for health and disease. Medicine and Science in Sports and Exercise 31(1): 38-45

59. Ferrari R, Ceconi C, Curello S, Guarnieri C, Caldarera M, et al. (1985) Oxygen-mediated myocardial damage during ischaemia and reperfusion: role of the cellular defenses against oxygen toxicity. J Mol Cell Cardiol 17(10): 937-945.

60. Ferreira AL, Matsubara LS (1997) Radicais livres: conceitos, doenças relacionadas, sistema de defesa e estresse oxidativo. Revista da Associação Médica Brasileira 43(1): 30-36.

61. Fiatarone MA, Marks EC, Ryan ND, Meredith CN, Lipsitz LA, et al. (1990) High intensity strength training in nonagenarians. JAMA 22(263): 30293034

62. Fridovich I (1989) Superoxide dismutases: an adaptation to a paramagnetic gas. J Biol Chem 264(14): 7761-7764.
63. Gaméz Meza N, Noriega Rodríguez JA, Medina Juárez LA, Ortega García J, Cázarez Casanova R, et al. (1999) Antioxidant activy in soybean oil of extracts from Thompson grape bagasse. Journal of American Oil Chemists Society 76: 1445

64. Gordon S, Davis BS, Carlson CJ, Booth FW (2001) ANG II is required for optimal overload-induced skeletal muscle hypertrophy. Am J Physiol Endocrinol Metab 280(1): E150-E159.

65. Hebbel RP (1986) Erythrocyte antioxidants and membrane vulnerability. The Journal of Laboratory and Clinical Medicine 107(5): 401-404.

66. Health GW, Hagberg JM, Ehsani AA, Holloszy JO (1981) A physiological comparison of young and older endurance athletes. J Appl Physiol 51(3): 634-640.

67. Holeck M (2002) Relation between glutamine, branched-che in amino acids, and protein metabolism. Nutrition 18(2): 130-133.

68. Huizenga JR, Tangerman A, Gips CH (1994) Determination of ammonia in biological fluids. Ann Clin Biochem 31(Pt 6): 529-523.

69. Ichimori K, Fukahori M, Nakazawa H, Okamoto K, Nishino T (1999) Inhibition of xanthine oxidase and xanthine dehydrogenase by nitric oxide. Nitric oxide converts reduced xanthine-oxidizing enzymes into the desulfo-type inactive form, J Biol Chem 274(12): 7763-7768.

70. Lew H, Pyke S, Quintanilha (1985) A Changes in the glutathione status of plasma, liver and muscle following exhaustive exercise in rats. Febs letters 185(2): 262-266.

71. Mcbreid (1998) Role of nitric oxide in skeletal muscle: synthesis, distribution and functional importance. Acta Physiol Scand 162(3): 401409.

72. Mcbride JM, Kraemer WJ, Triplett McBride T, Sebastianelli W (1998) Effect of resistance exercise on free radical production. Med Sci Sports Exerc 30(1): 67-72.

73. Melo PS (2007) Efeito anti-tumoral da desidrocrotonina: modulação do estresse oxidativo em animais portadores do tumor ascítico de Ehrlich. Rev Soc Brasileiras Câncer 14: 12-21.

74. Morin D, Hauet, Spedding M, Tillement J (2001) Mitochondriaas target for antiischemic drugs. Adv Drug Deliv Rev 49(1-2): 151-174.

75. Nagel E, Meyer ZU, Vilesdorf A, Bartels M, Pichlmayr R (1997) Antioxidative vitamins inprevention of ischemia/reperfusion injury. Int J VitamNutr Res 67(5): 298-306.

76. Paul AC, Rosenthal N (2002) Different modes of hypertrophy in skeletal muscle fibers. J Cell Biol 156(4): 751-760.

77. Reighlin S (1993) Neuroendocrine-immune interactions. N Engl J Med 329: 1246-1253.

78. Ross D, Moldeus P (1991) Antioxidants defense system and oxidative stress. In: Vigo-Pelfrey (edn), Membrane lipid oxidation. CRC, Florida, Boca Raton, Florida, USA, pp. 151-170.

79. Schneider CD, Oliveira RA (2004) Radicais livres de oxigênio e exercício: mecanismos de formação e adaptação. Rev Bras Med Esporte 10(4): 308-312.

80. Stathis CG, Febbraio MA, Carey MF, Snow RJ (1994) Influence of sprint training on human skeletal muscle purine nucleotide metabolism. J Appl Physiol 76(4): 1802-1809.

81. Swartz WM, Cha CJ, Clowes GH, Randall HT (1978) The effect prolonged ischemia on high energy phosphate metabolism in skeletal muscle. Surg Ginecol Obstet 147(6): 872-876.

82. Vina MJ, Gomez CA, Lloret R, Marquez JB, Minana FV, et al. (2000) Free radicals in exhaustive physical exercise: mechanism ofproduction, and protection by antioxidants. IUBMB Life 50(4-5): 271-277.

83. Walker V (2009) Ammonia toxicity and its prevention in inherited defects of the urea cycle. Diabets Obes Metab 11(9): 823-835. 
84. Welsh GI, Miller CM, Loughlin AJ, Price NT, Proud CG (1998) Regulation of eukaryotic initiation factor elF2B: glycogen synthase kinase-3 phosphorylates a conserved serine which undergoes dephosphorylation in response to insulin. FEBS Lett 421(2): 125-130.
85. Winjnen MH, Coolen SA, Vader HL, Reijenga JC, Huf FA, et al. (2001) Antioxidants reduce oxidative stress in claudicants. J Surg Res 96(2): 183-187. International License

For possible submissions Click Here

Submit Article

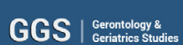

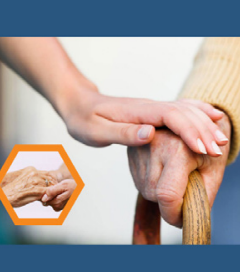

\section{Gerontology \& Geriatrics Studies}

\section{Benefits of Publishing with us}

- High-level peer review and editorial services

- Freely accessible online immediately upon publication

- Authors retain the copyright to their work

- Licensing it under a Creative Commons license

- Visibility through different online platforms 